\title{
PREDICTING SURVIVAL OF GRASS SHRIMP (PALAEMONETES PUGIO) DURING ETHYLNAPHTHALENE, DIMETHYLNAPHTHALENE, AND PHENANTHRENE EXPOSURES DIFFERING IN CONCENTRATION AND DURATION
}

\author{
Michael A. Unger,* Michael C. Newman, and George G. Vadas \\ Department of Environmental and Aquatic Animal Health, Virginia Institute of Marine Science, College of William and Mary, P.O. Box 1346, \\ Gloucester Point, Virginia 23062-1346, USA
}

(Received 16 May 2006; Accepted 9 October 2006)

\begin{abstract}
Both exposure duration and concentration determine the lethal consequences of polycyclic aromatic hydrocarbons (PAHs) released during oil spills. Many factors, such as weathering, tidal transport, and addition of surfactants, can change the composition of individual dissolved compounds and the duration over which an individual is exposed. Conventional toxicity testing methods produce effect metrics, such as the median lethal concentration (LC50), that are not applicable to predicting mortality at all toxicant exposure durations that are likely to occur during a spill. In the present study, survival time models were developed that explicitly include toxicant exposure duration and concentration to predict time-to-death for grass shrimp (Palaemonetes pugio) exposed to three PAHs (1-ethylnaphthalene, 2,6-dimethylnaphthalene, and phenanthrene) commonly found in the water-soluble fraction derived from oil. Conventional 48-h LC50s also were calculated for the compounds (ethylnaphthalene, $295 \mu \mathrm{g} / \mathrm{L}$; dimethylnaphthalene, $500 \mu \mathrm{g} / \mathrm{L}$; and phenanthrene, $360 \mu \mathrm{g} / \mathrm{L}$ ). In contrast to LC50s, survival models and associated response surfaces can be used to predict the proportions of shrimp that will die at various times throughout the exposure period.
\end{abstract}

Keywords-Survival analysis Oil spill Polycyclic aromatic hydrocarbons $\quad$ Toxicity Grass shrimp

\section{INTRODUCTION}

To predict the lethal impact of oil spills, it is important to understand the fate and effects of the individual compounds that make up these complex mixtures. To this end, researchers have studied the composition and relative toxicities of the various aliphatic, aromatic, and heterocyclic compounds released into waters from oil spills [1,2]. Although an understanding of the qualitative and quantitative chemical characteristics of the oil spill is important, the lethal effect that exposure duration has on receptors also must be quantified. Tidal variations, weathering, and application of surfactants can all alter the relative concentration and length of a toxicant exposure. Better predictive models are needed to assess the potential short-term and long-term effects to biota exposed to oil-derived toxicants. Survival models that explicitly include durations as well as concentrations have been applied to predict the effects of a variety of contaminants and to allow managers to make more effective decisions regarding spill response and remediation [3-6].

Most toxicity tests use a concentration-effect design that produces a lethality metric, such as a median lethal concentration (LC50) at a set exposure time (e.g., 96 h). A more encompassing approach exists to predict lethal consequences from realistic exposures, including pulsed, short-term, and long-term exposures resulting from oil spills. Occasionally, a few test durations might be used to coarsely predict how mortality changes with exposure time. Gross prediction is inevitable if mortality information is only collected for a few intervals. Temporal information is not included in the calculation

\footnotetext{
* To whom correspondence may be addressed (munger@vims.edu).

This paper is contribution 2788 of the Virginia Institute of Marine Science, College of William and Mary.
}

of individual LC50s, and the test concentrations are optimized for only one duration.

A further compromise arising in the conventional approach is that mortality occurring after exposure ends is not included in the calculated LC50, so it may underestimate the total mortality resulting from the toxicant exposure. In the few studies that have quantified postexposure mortality, it was found to vary widely and could be quite high $[7,8]$.

The conventional LC50 approach is not able to accurately predict all mortality from pulsed exposures or from exposure durations other than that used in the test. These weighty shortcomings impede accurate prediction of effects from oil spill exposures, which can vary in both duration and concentration through time and require prediction of all mortality resulting from a range of plausible exposure scenarios.

The main goal of the present work was to develop better models to predict the toxic effects of water-soluble polycyclic aromatic hydrocarbons (PAH) derived from oil spills. We conducted toxicity experiments with the grass shrimp (Palaemonetes pugio) exposed to three PAHs (1-ethylnaphthalene, 2,6-dimethylnaphthalene, and phenanthrene) representative of those found in the water-soluble fraction derived from oil [9]. Results from these exposure experiments were modeled with survival time methods [10] to produce models for each compound that predicted the proportion of individuals dying both during and after an exposure of specified duration and concentration. In addition, dosed shrimp were collected and analyzed for postmortem PAH concentrations to determine if accumulated PAHs were consistent with a critical body burden at the time of death.

\section{MATERIALS AND METHODS}

\section{Grass shrimp collection and maintenance}

Grass shrimp were collected locally from the York River and the Back River (both VA, USA) and were maintained in 
the laboratory in filtered water from the York River (salinity, 19-20\%o) for at least two weeks before use in the exposures. Shrimp were fed daily with Tetramin ${ }^{\circledR}$ Tropical flake food (Tetra Holding, Blacksburg, VA, USA). Individual shrimp with no outward signs of damage or disease were gently placed into glass tubes and the exposure aquaria $1 \mathrm{~d}$ before the exposures began.

\section{PAH survival analysis experiments}

Range-finding tests were conducted in May through August of 2005 to determine the concentration ranges to be used in the survival time experiments. The survival analysis experiments were conducted in August (ethylnaphthalene), October (dimethylnaphthalene), and November (phenanthrene) of 2005. Three replicates of four PAH concentrations and a control were prepared from saturated solutions generated with filtered water from the York River using techniques described in detail below. To minimize toxicant volatilization, exposure chambers were not aerated during the experiment, and solutions were renewed every $12 \mathrm{~h}$. All experiments were conducted under constant light from standard fluorescent light fixtures that were approximately $1.5 \mathrm{~m}$ above the aquaria. Experimental chambers were constructed from $25-\times 50-\times 58$ $\mathrm{cm}$ glass aquaria with glass lids. A water-tight glass partition was installed down the center of each aquarium to create tandem, 30-L exposure chambers of $25 \times 25 \times 58 \mathrm{~cm}$. This design reduced the surface area to volume ratio to minimize volatile losses of the PAH. One side of each aquarium was used to expose the test organisms, and the other was used to prepare the new test solution every $12 \mathrm{~h}$. Individual grass shrimp (26 shrimp/replicate) were placed in $2.8-\times 10.8-\mathrm{cm}$ 40-ml glass vials with an open-ended screw cap fitted with a stainless-steel mesh screen on one end. Shrimp were not sexed, but berried females were avoided when loading animals for the tests. The vials were suspended in the exposure chambers on aluminum racks to facilitate monitoring the condition of the test organisms and to allow easy transfer of the test organisms to newly prepared solutions every $12 \mathrm{~h}$. Shrimp were monitored for mortality every $4 \mathrm{~h}$ and scored as dead if no appendage movement was apparent. All dead shrimp were removed, weighed, and frozen. Shrimp that were still alive after the exposure period (ethylnaphthalene, $48 \mathrm{~h}$; dimethylnaphthalene and phenanthrene, $60 \mathrm{~h}$ ) were transferred to clean, filtered, and aerated water from the York River. This water was renewed every $12 \mathrm{~h}$, and shrimp were routinely monitored for latent mortality either for $48 \mathrm{~h}$ postexposure or until no latent mortality was apparent. At the completion of the test (48 $\mathrm{h}$ postexposure for ethylnaphthalene and dimethylnaphthalene, $60 \mathrm{~h}$ postexposure for phenanthrene), all shrimp were weighed and frozen.

\section{Generating PAH solutions}

A generator column was used to produce the saturated PAH solutions to avoid the use of solvent carriers for the time-todeath exposure experiments. Because as much as $350 \mathrm{~L}$ of saturated solution were required for each water renewal, a large $7.5-\times 59.2-\mathrm{cm}$ aluminum generator column was fabricated. It was packed with $3.8 \mathrm{~kg}$ of wet-sieved (mesh size, $>250$ $\mu \mathrm{m})$ sand that had been dried at $110^{\circ} \mathrm{C}$ overnight and ignited at $550^{\circ} \mathrm{C}$ for $4 \mathrm{~h}$ before use. The sand was coated $(0.1-0.7 \%$ $\mathrm{w} / \mathrm{w}$ ) with the analyte dissolved in an organic solvent (pentane or dichloromethane). The solvent was evaporated, and the column was then dry-packed with the coated sand. The column was fitted with pressure-sealed end caps and connected to a water pump (Poseidon PS3 "Silent" Titanium; Bayside Aquarium Supply, Anaheim, CA, USA) fed by sand-filtered, aerated, $20^{\circ} \mathrm{C}$ water from the York River. Column flow was adjusted to $2.0 \mathrm{~L} / \mathrm{min}$ by a $1.9-\mathrm{cm}$ gate valve. Before the dosing experiments, the solution flowing from the column was sampled and analyzed after flushing approximately $10 \mathrm{~L}$ to determine the actual concentration of the saturated effluent. Aerated water from the York River was mixed with the saturated solution directly in the dosing chambers to produce the four dosing concentrations. Contaminated or uncontaminated water from the York River was transferred from tanks via dedicated water pumps (Poseidon PS3 "Silent" Titanium). The tandem, 30-L test aquaria permitted filling one side with new exposure water and transferring the shrimp in racks from old to renewed water with minimal disturbance. Wastewater was pumped from aquaria to a reservoir and then passed at $500 \mathrm{ml} / \mathrm{min}$ over a 20-L activated carbon column to remove any PAH before disposal.

\section{Water chemistry}

Old and fresh test solution water chemistries were measured every $12 \mathrm{~h}$ and included temperature, dissolved oxygen, salinity, and pH. A Hydrolab Surveyor 4a (Hydrolab, Austin, TX, USA) was used for these measurements. Unfiltered water samples also were collected and frozen for ammonia analyses (SKALAR SAN Plus System continuous-flow autoanalyzer [Skalar, Inc, Norcross, GA, USA] using the phenol method).

\section{PAH analysis of water samples}

Exposure waters were analyzed for PAH concentrations using a high-performance liquid chromatograph (HPLC) with a fluorescence detector (Waters 600E Controller, Waters 474 Fluorescence Detector, and Waters 717 plus Autosampler with a 200- $\mu$ l loop [Milford, MA, USA] and a Grace VYDAC ${ }^{\circledR}$ C18 column [WR Grace, Hesperia, CA, USA]). The controller was programmed to run a gradient with water/acetonitrile starting with $100 \%$ HPLC-grade water to $70 \%$ acetonitrile at a flow of $1.0 \mathrm{ml} / \mathrm{min}$ over $35 \mathrm{~min}$. For all PAH analytes, the fluorescence detector excitation wavelength was $265 \mathrm{~nm}$, and the emission wavelength was $370 \mathrm{~nm}$. One hundred microliters of aqueous sample spiked with an internal standard (1-methylnaphthalene) was injected by the autosampler. Data from the fluorescence detector were collected and analyzed using ChemStation Software (Hewlett-Packard Santa Clara, CA, USA) and then stored on a NetServer LC 3 data system (Hewlett-Packard). Calibration of the HPLC method was performed for each PAH before sample analysis using an internal standard method and a seven-point calibration curve. Before the start of the shrimp scoping/exposure experiments, calibration standards were made in water from the York River taken from stock solutions of internal standard (1-methylnaphthalene, 0.38 $\mu \mathrm{g} / \mathrm{ml}$ ) and the PAH analyte of interest. Following calibration, 4.0-ml water samples collected from the generator column, stock tanks, shrimp exposure tanks (time, 0 and $12 \mathrm{~h}$ ), and waste stream were added to a vial containing $0.15 \mathrm{ml}$ of the internal standard in acetonitrile. The vials were immediately analyzed or frozen to minimize volatility losses. Once the analyses for a particular exposure were completed, the calibration of the HPLC was again verified with fresh standards.

\section{PAH analysis of tissue samples}

Shrimp tissues were analyzed for PAH concentrations by mass spectrometry using selective-ion monitoring. Individual 
Table 1 . Water-quality measurements in exposure aquaria ${ }^{a}$

\begin{tabular}{lccc}
\hline & & Exposure experiment & \\
\cline { 2 - 4 } & Ethylnaphthalene & Dimethylnaphthalene & Phenanthrene \\
\hline Temperature $\left({ }^{\circ} \mathrm{C}\right)$ & $20.6 \pm 0.3(n=38)$ & $20.6 \pm 0.4(n=50)$ & $20.5 \pm 0.4(n=50)$ \\
Salinity $(\mathrm{g} / \mathrm{kg})$ & $19.6 \pm 0.1(n=38)$ & $21.0 \pm 0.1(n=50)$ & $20.9 \pm 0.2(n=50)$ \\
Dissolved oxygen $(\mathrm{mg} / \mathrm{L})$ & $7.0 \pm 0.4(n=38)$ & $7.0 \pm 0.5(n=50)$ & $7.0 \pm 0.3(n=50)$ \\
$\mathrm{pH}$ & $7.78(6.91-8.01)(n=38)$ & $8.05(7.99-8.09)(n=50)$ & $7.89(7.42-8.00)(n=50)$ \\
Ammonia $(\mathrm{mg} / \mathrm{L})$ & $0.05 \pm 0.03(n=38)$ & $0.19 \pm 0.06(n=50)$ & $0.16 \pm 0.06(n=50)$ \\
\hline
\end{tabular}

a All values are presented as the mean \pm standard deviation except for $\mathrm{pH}$ values, which are reported as the median and the range (in parentheses).

shrimp were weighed, rinsed with deionized water, and placed into a 50-ml Teflon ${ }^{\circledR}$ centrifuge tube containing $2.0 \mathrm{ml}$ of concentrated hydrochloric acid and $500 \mathrm{ng}$ of deuterated $\mathrm{PAH}$ surrogate standards. The shrimp were homogenized with a spatula and ultrasonicated for $10 \mathrm{~min}$. The aqueous homogenate was extracted with two aliquots of hexane $(2.0 \mathrm{ml}$ each), centrifuged for $15 \mathrm{~min}$ at $8,950 \mathrm{~g}$ between extractions to separate the layers. The combined hexane extracts were reduced to $0.1 \mathrm{ml}$ under dry nitrogen, and $0.6 \mu \mathrm{g}$ of $p$-terphenyl internal standard was added before analysis on a Saturn 4D ion-trap mass spectrometer (Varian, Walnut Creek, CA, USA) operated in electron-ionization mode. Analytes and ions monitored were $p$-terphenyl internal standard $[152+230]$, naphthalene- $\mathrm{d}_{8}$ $[108+135+136]$, acenaphthene- $d_{10}$ [160-165], phenanthrene$d_{10}$ [187-189], chrysene- $d_{12}$ [239-241], perylene- $d_{12}$ [263266], 1-ethylnaphthalene $[141+155+156], 2,6$-dimethylnaphthalene $[141+155+156]$, and phenanthrene [176-179]. Sixpoint calibration curves were generated for each analyte, and identifications were based on retention time and matches to library spectra.

\section{Calculating LC50s}

The measured PAH exposure concentrations, number of dead shrimp, and total exposed shrimp were fitted by maximum likelihood estimation (MLE) to a log-normal model with the PROBIT procedure in the SAS ${ }^{\circledR}$ software (SAS Institute, Cary, NC, USA). Spontaneous mortality was included in the lognormal model, because low levels of mortality $(\leq 6 \%)$ occurred in the control shrimp during exposures. The 48-h LC50s and associated $95 \%$ fiducial limits were estimated with these models. Initially, log-logistic and log-normal models with spontaneous mortality were explored, but based on the associated chi-square statistics, the log-normal model was selected as the best-fitting model.

\section{Survival models}

Survival time was modeled as a function of PAH concentration using mean concentrations in each exposure tank and the LIFEREG procedure in the SAS software. The general approach was that described in detail previously (see, e.g., Newman [10]). Survival times noted at 4-h intervals were used directly in the model instead of applying interval censoring, because as detailed in Dixon and Newman [11], the fineness of the sampling used in these experiments minimized any inaccuracies arising from the minor discreteness of the sampling. Initially, models predicting time to death for shrimp as a function of In PAH concentrations were produced with three candidate models: log normal, log logistic, and Weibull. Akaike's information criteria (AIC) were then used to select the generally best model among these candidates (for details, see Newman [10]). The log-logistic model was chosen to predict sur- vival in an exposed population based on exposure concentration:

$$
\mathrm{TTD}=e^{\mu} e^{\beta}(\text { ln concentration }) e^{\sigma W}
$$

where TTD is the predicted time to death for a specified proportion of the exposed shrimp, $\mu$ is the MLE-estimated intercept, $\beta$ is the estimated coefficient for the influence of $\ln \mathrm{PAH}$ concentration on time to death, $\sigma$ is the MLE-estimated scale parameter, and $W$ is the response metameter for the model distribution associated with the dying proportion of the exposed shrimp for which the prediction is being made. The value of $W$ can be generated by special functions within most statistical or spreadsheet software or taken from tables such as Appendix Table 7 in Newman [10]. By changing the value of $W$, the various combinations of exposure concentration and duration can easily be found that result in the proportion of the exposed shrimp dying. However, prediction is only recommended within the range of concentrations and durations used in the tests from which the data were generated.

\section{RESULTS}

\section{Water chemistry}

Table 1 summarizes the temperature, salinity, dissolved oxygen, $\mathrm{pH}$, and ammonia for the three exposure experiments. Measurements were taken for freshly prepared solutions and for test solutions exposed for $12 \mathrm{~h}$. Measured parameters were within a narrow range for all exposure experiments.

\section{Toxicant concentrations}

The measured PAH concentrations are summarized in Table 2. Saturated solutions prepared by the generator-column technique had the following mean concentrations: Ethylnaphthalene, 6,510 $\mu \mathrm{g} / \mathrm{L}$; dimethylnaphthalene, $630 \mu \mathrm{g} / \mathrm{L}$; and phenanthrene, $500 \mu \mathrm{g} / \mathrm{L}$. These values proved to be the practical upper limit of dosing concentrations for dimethylnaphthalene and phenanthrene. Variation was present in PAH concentrations, because they were measured in both the newly prepared and the 12-h-old solutions. Average losses during the $12 \mathrm{~h}$ were as follows: Ethylnaphthalene, 9\%; dimethylnaphthalene, 17\%; and phenanthrene, $15 \%$. The PAH concentrations in all control samples were less than the detection limits $(1 \mu \mathrm{g} / \mathrm{L})$ during the exposures. Problems with incomplete mixing in some of the initial ethylnaphthalene replicates produced an unacceptable range in concentrations and increased variance in some replicate treatments. These outlier replicates were not included in the survival analysis. Careful mixing in subsequent experiments alleviated this problem.

\section{Survival analysis}

No latent mortality was apparent for the experimental shrimp exposed to ethylnaphthalene and to dimethylnaphthal- 
Table 2. Measured toxicant concentrations in exposure aquaria ${ }^{a}$

\begin{tabular}{lccc}
\hline & & Toxicant concentration $(\mu \mathrm{g} / \mathrm{L})$ & \\
\hline Treatment replicate & Ethylnaphthalene & Dimethylnaphthalene & Phenanthrene \\
\hline Concn. 1A & $-\mathrm{b}(n=8)$ & $300 \pm 30(n=10)$ & $150 \pm 20(n=10)$ \\
Concn. 1B & $310 \pm 40(n=10 \pm(n=10)$ & $150 \pm 20(n=10)$ & $160 \pm 20(n=10)$ \\
Concn. 1C & $310 \pm 40(n=8)$ & $290 \pm 70(n=10)$ & $220 \pm 40(n=10)$ \\
Concn. 2A & $400 \pm 40(n=6)$ & $380 \pm 70(n=10)$ & $230 \pm 30(n=10)$ \\
Concn. 2B & - & $380 \pm 60(n=10)$ & $230 \pm 30(n=10)$ \\
Concn. 2C & $370 \pm 40(n=8)$ & $390 \pm 60(n=10)$ & $300 \pm 30(n=10)$ \\
Concn. 3A & $490 \pm 70(n=8)$ & $470 \pm 100(n=10)$ & $300 \pm 30(n=10)$ \\
Concn. 3B & $440 \pm 40(n=8)$ & $470 \pm 70(n=10)$ & $300 \pm 40(n=10)$ \\
Concn. 3C & $480 \pm 40(n=6)$ & $570 \pm 70(n=10)$ & $380 \pm 40(n=10)$ \\
Concn. 4A & $-50 \pm(n=10)$ & $390 \pm 40(n=10)$ \\
Concn. 4B & $490 \pm 50(n=6)$ & $590 \pm 50(n=10)$ & $400 \pm 60(n=10)$ \\
Concn. 4C & $530 \pm 40(n=6)$ & $570 \pm 90(n=10)$ & \\
\hline
\end{tabular}

a Values are presented as the mean \pm standard deviation.

${ }^{\mathrm{b}}$ Replicate not used in survival analysis.

ene. Once shrimp were placed in clean water, they rapidly revived and returned to what appeared to be normal behavior. During the phenanthrene test, six shrimp died in the first 24 $\mathrm{h}$ postexposure. This represented less than $5 \%$ of the total mortality that occurred during the exposures. Mortality data collected during the phenanthrene experiment are plotted in Figure 1 and illustrate the cumulative mortality at 4-h intervals for the four toxicant concentrations as well as the lack of postexposure mortality. Similar results were obtained for ethylnaphthalene and dimethylnaphthalene. Conventional LC50s and $95 \%$ fiducial limits (in parentheses) were calculated: Ethylnaphthalene, $295 \mu \mathrm{g} / \mathrm{L}$ (162-331 $\mu \mathrm{g} / \mathrm{L})$; dimethylnaphthalene, $500 \mu \mathrm{g} / \mathrm{L}(463-535 \mu \mathrm{g} / \mathrm{L})$; and phenanthrene, $360 \mu \mathrm{g} / \mathrm{L}$ (333$402 \mu \mathrm{g} / \mathrm{L})$. Survival data were fitted to accelerated failure time models with the candidate survival time distributions of $\log$ normal, log logistic, and Weibull. For the three compounds tested, the log-logistic model was selected as the best choice based on the results of the minimum AIC estimation. Contours were developed from the models to predict shrimp mortality for various exposure times and toxicant concentrations (Fig. 2). Compound-specific model equations and conventional LC50s with 95\% fiducial limits also are included in Figure 2.

\section{Tissue concentrations}

Polycyclic aromatic hydrocarbon concentrations (wet wt) were measured in select whole shrimp that died during the exposure experiments. Ethylnaphthalene concentrations in tissue spanned a wide range, from $14 \mu \mathrm{g} / \mathrm{g}$ in the $300 \mu \mathrm{g} / \mathrm{L}$ treatment to more than $100 \mu \mathrm{g} / \mathrm{g}$ in the $525 \mu \mathrm{g} / \mathrm{L}$ treatment; tissue concentrations measured in shrimp from the 300 and $450 \mu \mathrm{g} / \mathrm{L}$ treatments are presented in Figure 3 for comparison. Tissue concentrations measured in dimethylnaphthalene- and phenanthrene-exposed shrimp also showed dose dependence and a corresponding wide range of values. At the time of death, concentrations ranged from 18 to $98 \mu \mathrm{g} / \mathrm{g}$ in shrimp from the dimethylnaphthalene experiment and from 30 to $500 \mu \mathrm{g} / \mathrm{g}$ in shrimp from the phenanthrene experiment.

All three PAHs were eliminated rapidly from the shrimp postexposure. Body burdens measured in phenanthrene-exposed shrimp that died during the depuration phase showed an exponential decrease in concentration with time. Elimination rate constants were calculated for each PAH from the slope of the log-transformed concentration data (Fig. 4). Corresponding half-lives ranged from 5.3 to $7.8 \mathrm{~h}$.

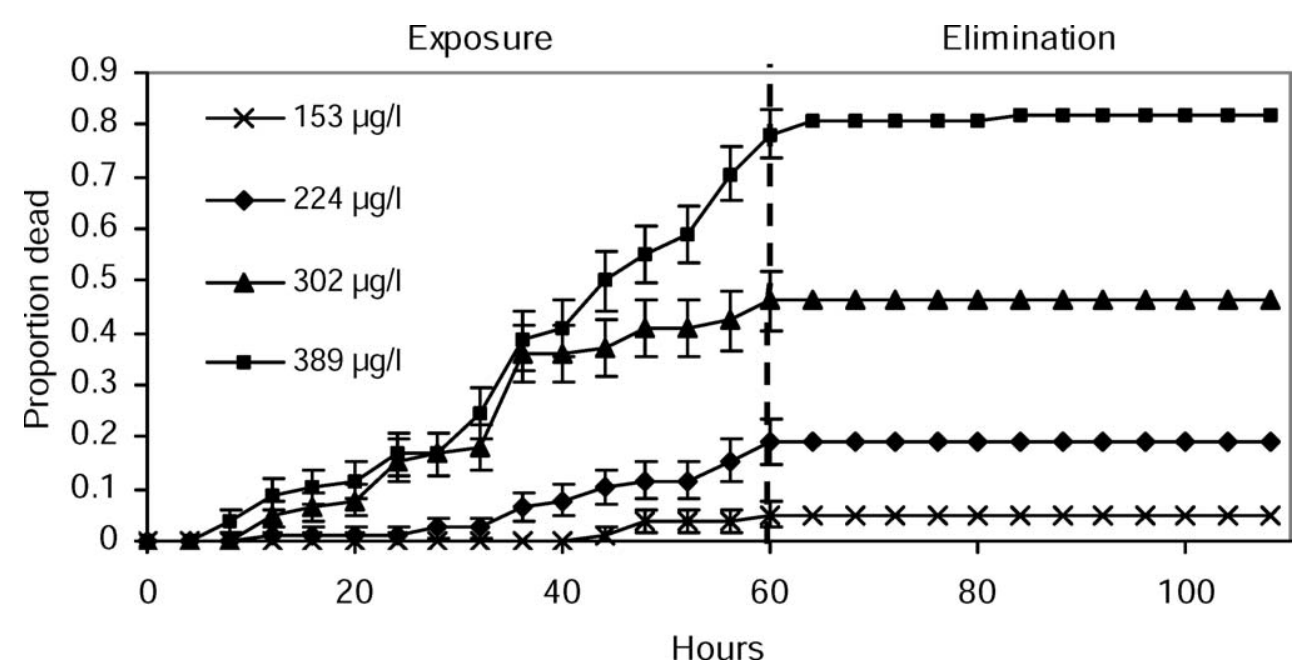

Fig. 1. Cumulative mortality at 4-h intervals for Palaemonetes pugio exposed to phenanthrene at four concentrations for $60 \mathrm{~h}$ followed by a 48 $\mathrm{h}$ elimination period in clean water. Little postexposure mortality occurred. Similar results were obtained for 1-ethylnaphthalene and 2,6dimethylnaphthalene. ( $n=78$ shrimp/concentration, 12 -h static renewals, standard errors calculated by SAS ${ }^{\circledR}$ [SAS Institute, Cary, NC, USA] using Greenwood's formula). 

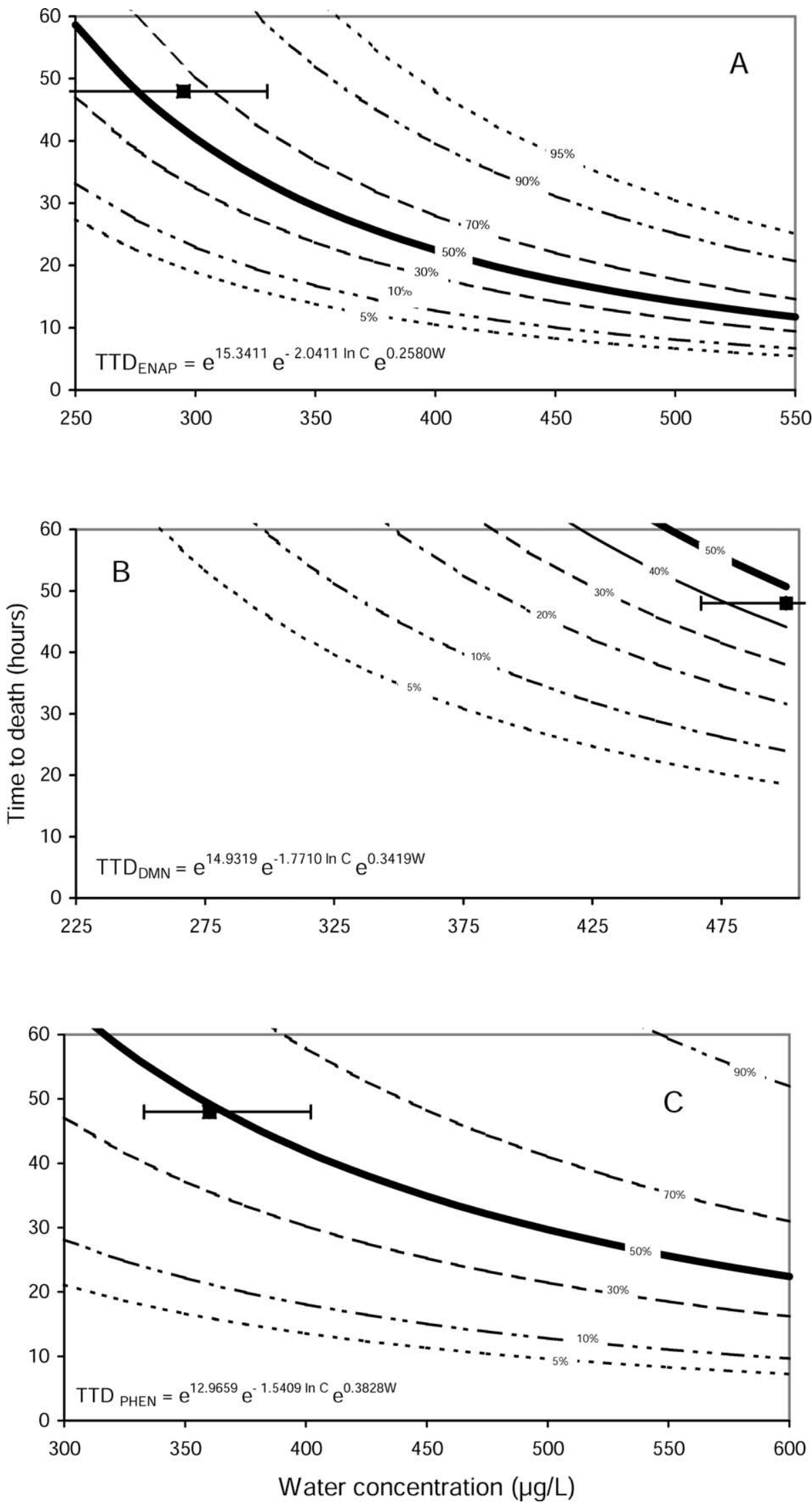

Fig. 2. Response surfaces predicting mortality levels for Palaemonetes pugio exposed to three polycyclic aromatic hydrocarbons (PAHs): (A) 1-Ethylnaphthalene, (B) 2,6-dimethylnaphthalene, and (C) phenanthrene. The survival models from which predictions are made also are given. Lines indicate different proportions dying predicted with the models for different combinations of exposure concentration and duration. The 48$\mathrm{h}$ median lethal concentrations (LC50s) and the 95\% fiducial limits are shown for comparison. TTD $=$ time to death. 


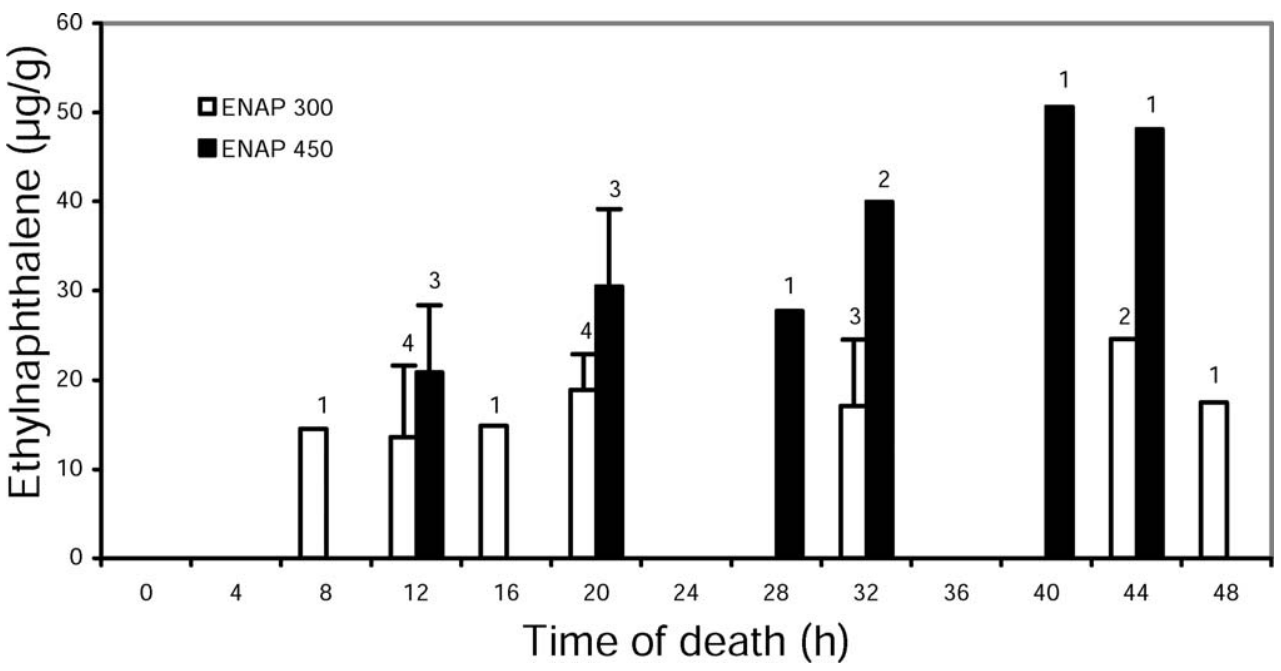

Fig. 3. Mean and individual whole-body concentrations ( $\mu \mathrm{g} / \mathrm{g}$ wet $\mathrm{wt}$ ) of 1-ethylnaphthalene (ENAP) measured in Palaemonetes pugio at the time of death. Shrimp from two exposure concentrations (300 and $450 \mu \mathrm{g} / \mathrm{L}$ ) ranged from 15 to $50 \mu \mathrm{g} / \mathrm{g}$. Numbers shown above each bar are the number $(n)$ of shrimp analyzed, and standard deviations are shown for $n>2$. A critical body burden was not evident for the acute exposures of ENAP used in these experiments. Similar trends were seen for 2,6-dimethylnaphthalene and phenanthrene.

\section{DISCUSSION}

The saturated solutions of ethylnaphthalene, dimethylnaphthalene, and phenanthrene produced in our experiments were 36 to $63 \%$ lower in concentration than those reported previously for these compounds in freshwater [12] (http://www. hbcpnetbase.com). This discrepancy likely resulted, in part, from reduced solubility in the cooler $\left(20^{\circ} \mathrm{C}\right)$, higher-salinity (20\%o) estuarine water used to make the test solutions. This trend has been documented for hydrophobic organic compounds in saline water [13], and it should be considered when conducting or evaluating toxicity experiments for estuarine species with hydrophobic organic compounds near the solubility limits. Although salinity has a significant effect on the solubility of PAHs, it has little effect on the toxicity or bioaccumulation of PAHs in larval $P$. pugio [14].

Conventional LC50s and 95\% fiducial limits (in parentheses) calculated for P. pugio were as follows: Ethylnaphthalene, $295 \mu \mathrm{g} / \mathrm{L}(162-331 \mu \mathrm{g} / \mathrm{L})$; dimethylnaphthalene, $500 \mu \mathrm{g} / \mathrm{L}$ (463-535 $\mu \mathrm{g} / \mathrm{L})$; and phenanthrene, $360 \mu \mathrm{g} / \mathrm{L}$ (333-402 $\mu \mathrm{g} / \mathrm{L})$. Surprisingly, the literature contains little information regarding the acute toxicity of these individual PAHs to $P$.

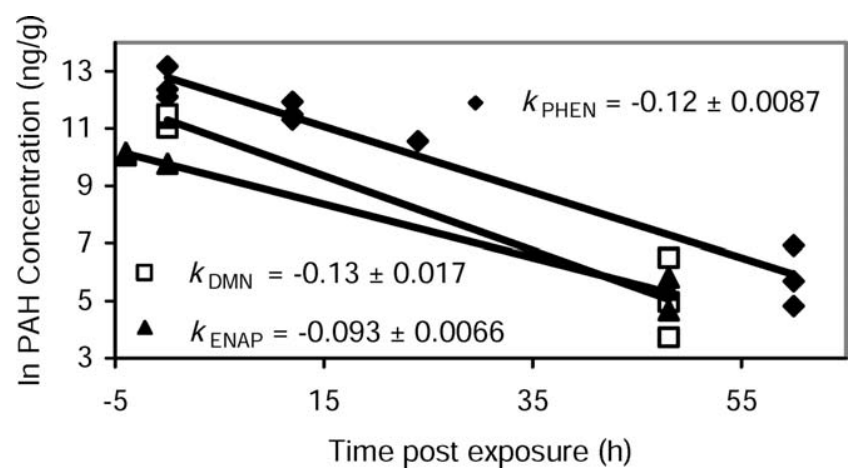

Figure 4. Elimination rate constants $(k)$ calculated for Palaemonetes pugio exposed to ethylnaphthalene (ENAP; $n=6$ ), 2,6-dimethylnaphthalene (DMN; $n=6$ ), and phenanthrene (PHEN; $n=9$ ). Individual rate constants are shown. All three polycyclic aromatic hydrocarbons (PAHs) were eliminated quickly by the shrimp, with corresponding half-lives of 7.8, 5.3, and 5.7 h for ENAP, DMN, and PHEN, respectively. pugio for comparison. Tatem and Anderson [15] did report a 48-h LC50 of $700 \mu \mathrm{g} / \mathrm{L}$ for $P$. pugio exposed to mixed dimethylnaphthalenes, which is in reasonable agreement with our results for 2,6-dimethylnaphthalene $(500 \mu \mathrm{g} / \mathrm{L})$. Looking at other aquatic crustaceans, 48-h LC50s of 617 to $780 \mu \mathrm{g} / \mathrm{L}$ were reported for dimethylnaphthalenes to the copepods Eurytemora affinis [16] and Oithona davisae [17]. Similar to the trend that we found for $P$. pugio, the 48-h LC50 for phenanthrene $(522 \mu \mathrm{g} / \mathrm{L})$ was lower than that for dimethylnaphthalene $(617 \mu \mathrm{g} / \mathrm{L})$ in $O$. davisae [17].

The PAH concentrations measured in whole shrimp at time of death varied by a factor of five and showed an increasing trend with dose (Fig. 3). Our acute exposure experiments were designed to develop time-to-death models and not to address toxicokinetics, so samples for tissue analysis were limited. However, these results suggest that body burdens from acutely toxic exposures are dose dependent and not good predictors of time to death for the compounds and the durations used in our experiments. A similar range in body burden concentrations was found for shrimp from the ethylnaphthalene (14$100 \mu \mathrm{g} / \mathrm{g})$ and dimethylnaphthalene (18-98 $\mu \mathrm{g} / \mathrm{g}$ ) exposures, but a higher range was found for shrimp from the phenanthrene (30-500 $\mu \mathrm{g} / \mathrm{g}$ ) exposure. Previous work has shown that critical body residues of various PAHs are similar on a molar basis $(7.5 \pm 2.6 \mu \mathrm{mol} / \mathrm{g}$; mean \pm standard error) when amphipods (Diporia sp.) were exposed for $28 \mathrm{~d}$ [18]. We saw a similar trend of increasing body burden concentrations with increasing molecular weight, but the range of body burdens at the time of death for each compound was greater than the compound to compound differences. Further work is needed on a wide range of PAHs to evaluate the utility of the critical body burden concept for predicting the toxicity of short-term acute exposures, such as those occurring during oil spills.

For all three compounds, prediction modeling was expedited, because very little latent mortality occurred. This is consistent with the results of Zhao et al. [8] and of Newman and McCloskey [7], in which minimal postexposure mortality was detected for pentachlorophenol-exposed Hyallea azteca and Gambusia holbrooki respectively.

Unlike the single LC50, the response surfaces generated 
with survival time models (Fig. 2) predict what proportion of an exposed population would be killed for a given combination of exposure concentration and duration. This type of information can then be used to predict the consequences to resident populations based on different exposure scenarios generated from field observations or computer simulations. An example would be to determine the consequences from adding surfactant to an oil spill on an incoming tide. Although surfactants enhance oil dissipation and protect on-shore species, their use will increase the dissolved PAH concentrations in waters because of diminished droplet size and increased solubilization. The duration of this increase will be a function of physical factors, such as dilution from mixing and volatility. If the increase and duration in dissolved PAH concentrations can be predicted based on known physical parameters, the manager can use survival models to estimate the increased risk to aquatic species and make an informed decision. Survival models can be expanded to include the combined effects from toxicant mixtures as well as other parameters that can influence toxicity, such as temperature, salinity, and light intensity. Combined with appropriate physical modeling, survival models can become valuable management tools. It is the intention of the authors to explore these effects in the near future.

Acknowledgement-We thank J. Carriger, J. Greene, E. Harvey, A. MacIntyre, and Y. Zhao for laboratory assistance. Funding for this research was provided by the Coastal Response Research Center (University of New Hampshire, Durham, NH, USA).

\section{REFERENCES}

1. Wang Z, Fingas MV. 2003. Development of hydrocarbon fingerprinting and identification techniques. Mar Pollut Bull 47:423452.

2. Barron MG, Podrabsky T, Ogle S, Ricker RW. 1999. Are aromatic hydrocarbons the primary determinant of petroleum toxicity to aquatic organisms? Aquat Toxicol 46:253-268.

3. Newman MC, Dixon PH. 1996. Ecologically meaningful estimates of lethal effect on individuals. In Newman MC, Jagoe CH, eds, Ecotoxicology: A Hierarchical Treatment. CRC/Lewis, Boca Raton, FL, USA, pp 225-253.

4. Lingtian Xie, Klerks PL. 2003. Responses to selection for cad- mium resistance in the least killifish, Heterandria formosa. Environ Toxicol Chem 22:313-320.

5. Sildanchandra W, Crane M. 2000. Influence of sexual dimorphism in Chironomus riparius MEIGEN on toxic effects of cadmium. Environ Toxicol Chem 19:2309-2313.

6. Widianarko B, Van Straalen N. 1996. Toxicokinetics-based survival analysis in bioassays using nonpersistent chemicals. Environ Toxicol Chem 15:402-406.

7. Newman MC, McCloskey JT. 2000. The individual tolerance concept is not the sole explanation for the probit dose-effect model. Environ Toxicol Chem 19:520-526.

8. Zhao Y, Newman MC. 2004. Shortcomings of the laboratoryderived LC50 for predicting mortality in field populations: Exposure duration and latent mortality. Environ Toxicol Chem 23: $2147-2153$.

9. Neff JM, Stout SA, Gunster DG. 2005. Ecological risk assessment of polycyclic aromatic hydrocarbons in sediments: Identifying sources and ecological hazard. Integr Environ Assess Manag 1: 22-33.

10. Newman MC. 1995. Quantitative Methods in Aquatic Ecotoxicology. CRC/Lewis, Boca Raton, FL, USA.

11. Dixon PM, Newman MC. 1991. Analyzing toxicity data using statistical models for time to death: An introduction. In Newman MC, McIntosh AW, eds, Metal Ecotoxicology. Concepts \& Applications. CRC/Lewis, Boca Raton, FL, USA, pp 207-242.

12. Lide DR. 2005. CRC Handbook of Chemistry and Physics, Internet version. CRC, Boca Raton, FL, USA.

13. Gordon JE, Thorne RL. 1967. Salt effects on nonelectrolyte activity coefficients in mixed aqueous electrolyte solutions-II. Artificial and natural seawaters. Geochim Cosmochim Acta 31: $2433-2443$

14. Weinstein JE. 2003. Influence of salinity on the bioaccumulation and photoinduced toxicity of fluoranthene to an estuarine shrimp and oligochaete. Environ Toxicol Chem 22:2932-2939.

15. Tatem HE, Anderson JW. 1973. The toxicity of four oils to Paleomonetes pugio (Holthuis) in relation to uptake and retention of specific petroleum hydrocarbons. Am Zool 13:1307-1308.

16. Ott FS, Harris RP, O'Hara SC. 1978. Acute and sublethal toxicity of naphthalene and three methylated derivatives to the estuarine copepod, Eurytemora affinis. Mar Environ Res 1:49-57.

17. Barata C, Calbert A, Saiz E, Ortiz L, Bayona JM. 2005. Predicting single and mixture toxicity of petrogenic polycyclic aromatic hydrocarbons to the copepod Oithona davisae. Environ Toxicol Chem 24:2992-2999.

18. Landrum PF, Lotufo GR, Gossiaux DC, Gedeon ML, Lee JH 2003. Bioaccumulation and critical body residue of PAHs in the amphipod, Diporeia sp.: Additional evidence to support toxicity additivity for PAH mixtures. Chemosphere 51:481-489. 